\title{
Language diversity in mathematics education research: a move from language as representation to politics of representation
}

\author{
Anna Chronaki ${ }^{3,4} \cdot$ Núria Planas ${ }^{1,2}(1)$ \\ Accepted: 8 May 2018 / Published online: 16 May 2018 \\ (c) The Author(s) 2018
}

\begin{abstract}
We discuss language diversity in mathematics education research by considering the move from a view of language as representation that strives to correlate concepts, ideas, codes and signs towards addressing the representation politics of language. Language as representation of mathematics has framed the discursive construction of language diversity over the years in published research in our field. We argue that the representation politics of language as grounded in cultural and postcolonial studies enables us to see the meanings attributed to language diversity as resulting from a complex 'circuit of culture' in the realm of global and local identity politics. Three questions help us in this endeavour: (1) What are assumed as commonly shared meanings about language diversity? (2) How do they become present in prevailing discourses about the languages of mathematics, teachers and learners? (3) How may a view of language diversity as part of the 'circuit of culture' disturb the normative presence of such assumptions?
\end{abstract}

Keywords Mathematics education research $\cdot$ Language $\cdot$ Language diversity $\cdot$ Politics of representation $\cdot$ Cultural and postcolonial studies · Circuit of culture

\section{Introduction}

Although today theories have become vital lenses through which the world can be interpreted, they remain partial in how much they allow us to see, perceive or sense. To date, several theories have served mathematics education research to address the societal phenomenon of language diversity, and a great number of studies have contributed from a variety of standpoints to theorize language. Language diversity is increasingly considered as tantamount to the declaration of language as a pedagogic and epistemological resource for mathematics teaching and learning. The move away from deficit perspectives towards culturally responsible practices

Núria Planas

Nuria.Planas@uab.cat

1 School of Education, Universitat Autònoma de Barcelona, Cerdanyola del Vallès, Catalonia-Spain, Spain

2 Department of Mathematics Education, University of South Africa, Pretoria, Gauteng, South Africa

3 School of Humanities and Social Sciences, University of Thessaly, Volos, Greece

4 Department for Mathematics and ScienceTeaching, University of Malmö, Malmö, Sweden in mathematics education (Hunter et al. 2018) is occurring under the umbrella of the language as a resource metaphor. However, this move tends to remain captured within the language as a representation standpoint that regards mathematics, and its teaching or learning, as the performing of specific norms grounded in cultural practice. In this paper, we explore the move from language as representation to language as representation politics and consider its effects on language diversity configurations in mathematics education research. Language as representation infers a view of mathematical language as a system of representations of an ideal universe of mathematical objects (e.g., numbers, algorithms, models) in certain codes and signs that tend to imitate or imagine the world but can also exist independently. In contrast, language as representation politics implies a view of mathematical language as not merely situated in local cultural communities but as the means for re-signifying potential identity and difference. Representation politics reveals the assumed norms produced in relation to mathematics, learner or teacher, and allows us to consider them as part of a broader curricular, schooling and societal politics. We argue that mathematics education research on language diversity can gain from moving from language as representation, which tends to fix mathematical meanings, towards 
language as representation politics, which acknowledges language diversity as a key for re-signifying the cultural practice of mathematics education itself. This is important in a world that urges us to consider: "How many people today live in a language that is not their own? Or no longer, or not yet, even know their own and know poorly the major language that they are forced to serve?" (Deleuze and Guattari 1987, p. 19).

This paper discusses current research studies in the domain of language and mathematics education to determine how such works help us consider: (1) What are assumed as commonly shared meanings about language diversity? (2) How do they become present in prevailing discourses about the languages of mathematics, teachers and learners? (3) How may a view of language diversity as part of the 'circuit of culture' disturb the normative presence of such assumptions? Before addressing these questions, we first discuss language diversity in mathematics education research and then move on to consider the epistemic views of language as representation and as representation politics. Based on evidence from the available literature, in the subsequent three sections, we revisit language diversity-i.e., how it is viewed and, by implication, represented - taking into account the move towards the politics of representation, and we discuss its effects on views of the languages of mathematics, learners and teachers. The paper ends with some concluding remarks on how this move might affect our research on language diversity.

\section{Language diversity in mathematics education research}

Language diversity has become a focus in mathematics education research in recent decades. Despite early concerns about bilingualism being detrimental to learners' linguistic, cognitive and educational growth in mathematics (Austin and Howson 1979), which promoted a deficit perspective of the learner, we know today that what matters is not the quantity of languages that learners deal with but the social and cultural circumstances of language use in mathematics teaching and learning (Secada 1992). Particular emphasis is placed on multilingual classrooms where teachers and learners may not share the same home languages or may have to work in an imposed language (Setati and Adler 2000), as a result of colonial histories or globalized practices that result in specific policies on language use in education. Studies with this emphasis support a shift away from a deficit perspective and towards embracing the multiple languages of learners as a pedagogic resource in the mathematics classroom (Planas and Civil 2013). Although some studies acknowledge the inherent heteroglossia in mathematics classrooms (Barwell 2016), or the embedded hybridity and dialogicality in mathematical language use (Chronaki 2009, 2011), the resource metaphor seems to prevail.

The shift from deficit to resource perspectives has occurred in a context of language theorizations related to syntactics (i.e., how signs and symbols relate in sentence structure), semantics (i.e., how signs and symbols relate with things to which they refer) and pragmatics (i.e., how signs and symbols relate to users). Nonetheless, resource perspectives still provide answers for language and language diversity as part of pedagogical and didactical organizations of the mathematics classroom (Planas and Setati-Phakeng 2014). The metaphor of language as resource evolves primarily as a construct of classroom-based research and, as such, links the discussion of language diversity to problems and solutions of school mathematics teaching. Being in line with prevailing work on lesson study data, it fails to consider language diversity in its broader cultural, social, political and historical context. Despite the importance of putting forward ways of seeing language use as representing mathematical concepts, we need to consider how language use is not merely about a fluent and competent performance with mathematical signs, but rather it evolves around global and local language politics.

First, such language politics might refer to histories of imperial or minor communities resorting to their linguistic and cultural capital or heritage as a means of struggling for power, survival or autonomy. Ethnic and diaspora communities, bilingual societies and nomadic people or travellers in Europe reclaim their identities by reclaiming language rights. In this realm, specific groups enter battles to preserve or revitalize marginalized or vanished home languages. Such attempts produce language diversity considered as a will to recognize the presence of people who speak a language different to the one that prevails as the state or imposed cultural norm in specific localities (e.g., Latino/as in the U.S., Catalans in Spain, indigenous people in Brazil, and groups of migrants, refugees and war-affected populations in Europe). Realizations of language diversity in the school context influences how schools operate in relation to curriculum practice with serious effects on how we now need to reconsider mathematics teaching and learning.

Second, language politics becomes part of contemporary bio-politics (Foucault 1972). The extended governing of people's lives via systems of representation-such as linguistic signs and codes-has implications when we encounter population movements across and within borders due to unemployment, poverty, environmental calamity or war, but also youth cultures or cultures around a range of abilities. This is the case for technology related, blind and deaf people's, and aesthetic cultures that emphasize poetry, literature or the arts. Today, we need to consider nomadic or youth cultures and their vernacular or colloquial languages used in their everyday localities, where an increased use of pop 
culture, social media and digital texts tends to recreate and transform the context for communicating mathematical ideas and activity (De Freitas and McAuley 2008). An increased spread of languages via contacts between minor and dominated groups highlights a growing realization of language diversity framing complexity in our worlds and worldviews that also affects language use in mathematics classrooms.

Taking the above into account, one may think that it is not clear which and whose languages become a pedagogic resource in the mathematics classroom, for whose purposes or interests. It is not even clear what might be the effects of our research practices when the importance of learner languages is claimed as a resource for mathematical learning without considering the broader context of language politics and biopolitics. By paying attention to the variety of language use options, we might be able to understand the global and local politics with regard to mathematics and mathematics learning, and disturb, disrupt and interrogate certain language use as the norm of the multilingual mathematics classroom. According to Mufwene (2002), it is not always the power of top-down policies, but the local socio-economic and cultural ecologies that determine the communicative behaviour and choices of people, which have consequences for language evolution.

Today, we face a rapid expansion of mathematics education research on language (Planas et al. 2018) while, simultaneously, we confront the "maths for all" global call for social justice. Mathematical ability is coupled with the requirement to develop the language skills of the competent rational problem-solver. Thus, it is timely to explore what is emphasized and what is left concealed when language diversity is discussed as a matter of mathematics education for all. This is important at a time when language as resource is a major unquestioned premise, approached as the prevailing politically correct way to think of language diversity. Encountering the politics of language diversity implies a profound epistemological shift from seeing language and, in turn, language diversity, as a given norm, towards interrogating that norm. Next, we situate the discussion of language and language diversity in a paradigm that uncovers the politics of representation of certain language uses and groups of speakers as appropriate, where appropriate means that they work, deliberately or not, to preserve the circulation of particular truths.

\section{Language use: representation and/ or representation politics}

Representation as a theoretical notion has prevailed in mathematics education research where the language of mathematics tends to be equated with the representational practice itself. For some, the discipline of mathematics and, hence, mathematics education, are about the study of representations and, specifically, the language of representing natural, physical or social phenomena through particular orderings, abstractions, symbols, signs, models and applications. In mathematics education, the view of knowledge as a mirror of nature has tacitly influenced a number of pedagogic approaches framed within the realm of realistic contexts, didactical phenomenology, ethno-mathematics or critical mathematics. Despite critiques ranging from the diverse viewpoints of radical constructivist, sociocultural or poststructural theories addressing the epistemological conflicts, dead ends and paradoxes of 'representation', we note its lasting impact on how language and language diversity are still approached today. This influence is evident in the ways curricular reforms in the sphere of educational policies or pedagogic experimentations in classroom practices embrace language diversity by accepting representation without questioning potential effects on the language of mathematics, learner or teacher. In this section, we revisit language as representation in mathematics education and encounter language as representation politics. We aim to explore how a view of language as representation influences discussions of language diversity, but also to highlight potential openings that a view of language as representation politics can offer.

We do not argue for an opposition but rather a distinction between the view of language as representation and the representation politics of language. There are examples of the unavoidable coexistence of elements of these two approaches. Indeed, language-based research in mathematics education cannot be claimed as the exclusive property of either the representational or the representation politics approach alone. Together with the traceable distinction between language as representation - primarily interested in the representation of mathematics as an essentialist body of knowledge evolved in particular cultures-and the representation politics of language-primarily interested in the politics of representation of (multilingual) mathematics teaching and learning - we find intermediate positions. The use of Hallidayan social semiotics in the work of Morgan is an example of understanding language as representation of our world experiences, including the representation politics involved in mathematics teaching and learning. Morgan (2006) illustrates a theoretical grounding that, while taking a representational view of language, goes beyond the study of the mind to examine the situated production of discourse. Such intermediate positions address issues of reading, interpreting and understanding representations of mathematics, but without allowing their radical interrogation. We see these positions as evidence of the continuum of possibilities between the two approaches addressed in this paper. One of the underlying assumptions embedded in this scale is that the view of language as representation is not to be taken strictly in the cognitive, psychological or 
linguistic sense, namely the exclusive location of language in the mind. Intermediate positions agree that investigation into cultural and social features of the context of mathematics teaching and learning is crucial to an understanding of language as representation. This is in line with what is often called the social turn in mathematics education research but does not necessarily interact with work within the sociocultural-political axis (Planas and Valero 2016).

\subsection{Language as representation of mathematical ideas}

Etymologically, the notion of representation can be understood as a presentation drawn up not by depicting the object as it is but by representing it in a new form, context or space (i.e., in the form of constructing, writing, reading, speaking, narrating or rehearsing). Although the term embraces a range of meanings and interpretations, in ancient times representation played a central role in studying and circulating literature, artwork and aesthetics. The construct has evolved into a significant component to analyze the contemporary world's creation of images in a range of domains, as well as visual or textual arts, films, exhibits, literature and crafts. Mathematics has been central in philosophical approaches to representation, especially in classical analytic philosophy and phenomenology, viewing knowledge as a mirror-like representation of the physical world. For Rorty (2009), the idea of mind as mirror pertains to the notion of knowledge as accuracy of representation, where a view of knowledge as mirroring real phenomena drives endeavours towards "getting more accurate representations by inspecting, repairing and polishing the mirror" (p. 12) through language.

Following the metaphor of mind as mirror, mathematics education research on language traditionally discusses issues related to how the mind engages with reading, interpreting and understanding representations expressed through language in text or talk. Much research has evolved around the binary notion of internal and external representations that serve to objectify the abstract nature of mathematical ideas and to map mental constructs (i.e., internal representations as the work of the mind) and physical phenomena (i.e., external objects that mirror the mind). As such, the material figure of a square serves to visualize the concept of a square; a collection of five items maps the notion of number five and so on (Janvier 1987). On endeavouring to make sense of such mirroring attempts between internal and external representations (or mind and nature), language becomes a pivotal vehicle and hence problems arise. Several scholars (e.g., Vergnaud 1997) have discussed problems around either creating accurate representations of mathematical ideas or bridging the chasm between internal and external representations. Studies focusing on mathematical register have embraced language as a toolkit of mathematical concept representation. This view persists in studies on varied representations of mathematical concepts through a range of media forms such as haptic, digital or textual. This is also the case in studies on didactic or pedagogic bridging between internal or mental and external or material representations of reality or the perceived reality of social, natural or physical phenomena, often via mathematical models, applications and narratives. Under this view, mathematical ideas are what remains encoded in signs, exists independently from any agent and involves a fixed language that strives for accuracy and certainty. Duval (1995) has referred to the transformation of semiotic representations and the transference of conceptual meanings across them. This influential line of work situates representations at the interplay between external and internal significations of mathematical concepts, whilst establishing a clear distinction between the functions in teaching and learning of the so-called natural languages and of the mathematical register (Steinbring 2005).

The view of language as representation of our experiences of mathematics - tacitly implying, but without explicitly naming the Western roots of what we call today 'global' mathematics - is mostly presented alongside the experiences of learning and teaching one particular culture of mathematics, regardless of the diversity of languages and cultures in the context. The problem with not discussing what is meant by 'mathematics' is that language-based research tends to look at language diversity in the mathematics classroom as the right of groups to use their languages instead of their right to produce mathematics-based discursive spaces that create opportunities for participation in learning. Earlier attempts to problematize language as representation have focused on discussing the chasm or the gap between internal and external representations as the learning paradox of seeing the same object but holding different ideas (Mason 1987), or the transfer problem across contextualized representations and arguing for knowledge as situated (Lave and Wenger 1991). Sfard (2008) has also influenced research on moving from a view of language as representation by considering mathematics learning as the initiation towards using specific semiotic systems. Instead of representations, she speaks of the realization of mathematical objects to mean that the communication amongst participants about an object is what gives the object existence. The interpretation of mathematical objects as discursive objects within the language of mathematics is a step towards the re-signification of the problem of representation, and the cultural-historical notion of representation by Radford (2006) is another step forward. Nonetheless, and despite differences in theoretical grounds and epistemological positions, representations are similarly taken as ways of accessing the world and constructing mathematics. This is so even in studies with communities at risk. Edmonds-Wathen (2014) examines the aboriginal English spoken by indigenous children in remote 
communities in the Northern Territory of Australia to see how language affects description and use of spatial terms like "in front of" and "behind". In that work, language and language diversity are discussed in relation to how learners represent certain universal mathematical ideas, regardless of whose worldviews are more closely aligned with the embedded mathematical reality.

\subsection{Language as representation politics}

As already mentioned, the notion of representation refers to ways of depicting an idea or an object through a particular new form of presenting it to the social or public domaini.e., the act of re-presenting it-. By thinking of representation as the act of representing or presenting, again and anew, an object, a concept, an idea or even a practice or culture in the public realm, its political character is appreciated and acknowledged. Hall (1997) addresses the role of representation in making and distributing culture as the co-construction of identity, conduct regulation, the socialization of the newcomers or youth, the experience of rituals, or the initiation into production and consumption habits-i.e., the circuit of culture in du Gay et al. (1997)—. Key to this circuit is the issue of language, as it serves to represent thoughts, ideas, feelings and emotions, or to create and reify shared meanings amongst people in a culture. Representation involves an understanding of how language and systems of knowledge production work together to produce and circulate meaning, turning it into shared truth. We assign meaning to things, people and events in systems of representation. For example, representations work towards creating images of the self and the other, embedded in discourses informing policies and practices. The politics of representation thus evolves around issues of power aiming to govern, discipline and regulate one's own image and care of the self in relation to the other.

Language as representation contributes towards constructing identity and difference by creating binary oppositions in which one pole tends to dominate (e.g., male over female, us over them, high over low), bringing issues of power to the fore. Representing the other has resonances with long-standing practices of domination within contexts of colonization, anticolonial and decolonial struggles. Said (1997), employing a Foucauldian conception of power/knowledge, demystifies the construction of 'the other' through a linear uninterrupted historical narrative of the Orient in literary texts as 'other' and thus different to the civilized West. He provides the rationale for colonial oppression by strengthening the hegemonic identity of Western culture. Despite challenges to his work, it still helps scholars to analyze representations that demarcate us versus them. Spivak (1988) argues for the importance of reconsidering 'representation' in a literary or semiotic sense as always connected with representation in politics. Her sense of representation is any capacity for a person to be the agent of, to stand for, the will of other people. She links representations, especially in the contexts of marginalized groups from the so-called developing countries, to identifying processes to facilitate, mediate or support their presence in socioeconomic, gendered, cultural, geographic, historical and institutional ecologies. Representations of the developing world conflate two related contrasting meanings of representation, speaking for versus speaking about. Whilst speaking for is about representing or voicing the other, speaking about is configuring the image assigned as 'other'. Given that representations can never escape 'othering', Spivak argues for the need to encounter its politics and interrogate its power relationships.

The politics of representation supports exploring how coupling language and representation contributes to producing shared meanings of othering as part of the circulation of a culture. Hall (1997) explains how language is the privileged medium of meaning production and how we share meanings through our common access to language. Foucault (1972) argues that the discursive formation of shared meanings as regimes of truth or norms fabricates what is normal and what is not. As such, specific representations of the abnormal or the other are constructed as different in direct comparison to what is taken as normal and, thus, the objects of the representations are excluded or abjected. Discourses embrace the coupling of representation and language and work as governing mechanisms for the circulation of shared meanings, channelling the discursive formation of truths that determine the construction of identities and the production of difference. The emphasis towards creating 'shared meanings' denotes how meaning is inherently political, as it becomes part of regulating and organizing practices and conduct amongst people as they contribute to setting norms and conventions. Thus, representation politics encourages us to approach language as part of governing mechanisms or as the biopolitics of our semiotic and discursive experiences. The field of semiotics relates culture and representation through signs and symbols, and is concerned with the how of meaning production via chains of signification often seen through the poetics of language. Meanwhile, a view of language as representation politics interrogates the social process of knowledge construction and provides ways of resignifying cultures and identities. Below, we address language diversity in mathematics education by considering what might be the representation politics of mathematics, learner and teacher. Our driving questions are: (1) What are assumed as shared meanings produced about language diversity? (2) How are they present in prevailing discourses about the languages of mathematics, teacher and learner? (3) How may the view of language diversity as part of the 'circuit of culture' disturb the norms of such assumptions taken as shared meanings? 


\section{Language diversity and representations of the language of mathematics}

Discussions concerning language diversity often equate this notion to linguistic diversity and, hence, expressions like linguistically homogeneous and linguistic barriers / discontinuities / differences prevail in the literature available. These expressions denote the semiotic and indexical character of language at the expense of its broader discursive, organic and political nature. This is the case in the early work of Gorgorió and Planas (2001), where language was conceptualized as a vehicle in the construction of mathematical knowledge. At that time, the researchers were dealing with the massive inclusion of migrant children and the co-existence of varied languages in the classroom unknown to each other (e.g., languages from the Maghreb region and Southern Asia). The perceived challenge was to make the mathematical register present in the context of the multilingual classroom. Language diversity thus became the analogy of mathematical register diversity, since language use served to represent that plurality. As Pirie (1997) wrote: "How can one know what and how much understanding is encapsulated in students' own use of the mathematics register, unless the students can also express themselves in everyday language and function with the symbolic representation?" (p. 229). However, such a view entails the tacit recognition of a certain linguistic form of mathematical register valued as the ultimate form of language for mathematics teaching and learning.

The view of representation politics gives rise to numerous questions: What is concealed when a certain norm of mathematical register prevails? Can we interrogate the fixity of meanings that objects, people and events seem to carry in the context of use of the language of mathematics in the classroom? How is this fixity disturbed by students who speak different languages? How do meanings shift as we move from one culture to another, or across contexts and communities that students bring with them to the classroom? How does the visual, material or bodily language of school mathematics serve to represent varied cultures and identities? What might be the global and local politics of such representations? Here we find the hegemony of Western mathematics and its register, together with the fabrication of ethnomathematics and everyday languages as the exotic other. Under such a view, language is also a vehicle, but geared toward the dissemination of meanings around a particular mathematical reality and the communities that own it. For some communities, this becomes a major focus when they try to preserve their identity by preserving their language (e.g., by the creation of dictionaries that map oral languages). Whilst such attempts are important, they need to be encountered as part of broader global and local language politics (e.g., Catalan in Spain, multiple languages in
South Africa) that creates a public space of representing the other through home languages. We still need to explore how such representations are experienced, interpreted or used, by whom (i.e., youth, stakeholders) and for whom (learners as citizens). Mathematical meanings through representations (that work through languages) operate as part of a nexus of cultural practices that penetrate society and create public images of school mathematics. Taking into account the circuit of culture, we can see how language use in the school mathematics curriculum serves to recreate identities, not without the resistance of certain communities (e.g., diaspora and indigenous communities who strive to create their own curricula) towards what is assumed as the state language.

Researchers in mathematics education resort mainly to the discourse of language as pedagogic resource and downplay the broader language diversity politics in education. Even if we claim that languages are resources for mathematics learning, we can still revisit their role in cultural circulation and problematize the issue of which mathematics frames the objects of learning in ways that encourage us to become creative and culturally responsible. By thinking of language as both resource and politics, we can consider how linguistic signs and registers, in their varied oral, visual and gestural modalities, form part of exchanges and continuous transformations. Christianidis (2004) discusses how specific developments in the history of Greek mathematics form part of cultural exchanges between local communities. If we consider meaning in school mathematics, one may argue that the use of certain linguistic signs, codes and registers serves global and local interests through curricular politics. The place of language and language diversity is essential in understanding how the language of mathematics, together with language diversity, serves to perpetuate certain discourses of civic society or the global world. We can discern how particular representations serve and sustain the production of who is mathematically able through language use and, thus, reflect on its effects in mathematics classrooms where language diversity is in focus and the fabrication of difference is at stake. Gal (1989) observes how employing the skill to use a specific language to represent reality is not an innocent or value-free practice. Issues related to who controls a particular representation of an imagined reality, and thus makes it minor or exotic, is a source of power but also a space of conflict and struggle denoting its part in hegemony. Language diversity, in this sense, can disturb certain norms of signifying practices tied up with mathematical knowledge, identities and cultures. 


\section{Language diversity and representations of the learner}

The literature in the domain brings up certain images of the diverse learner as being a representative species of a culture, ethnic minority, ability group, and so on. The language-diverse learner is represented as moving across languages and as struggling to achieve a double entry into global learning. This entry becomes possible, first, through mastery of the state or hegemonic language and, second, through encountering mathematics as a key for citizenship. Discourses of mathematical ability as the ability to speak the language of mathematics and of the teacher through the state language are entangled. Several authors interpret the language of the diverse learner as the one that needs to grow by incorporating languages other than those spoken in the family and with friends. Prediger et al. (2016) link codeswitching to multilingual learners' "difficulties in comprehension of the problem-tasks or keywords and phrases" (p. 200). Rather than viewing codeswitching as intrinsic to language use, this perspective engages us with the challenges of language translation and separation. Drawing on representation politics, the process of signifying difference across languages by focusing on mathematical registers in need of translation may easily turn into a chain of significations where difference is construed around learners and their mathematical ideas. Thus some learners are represented as potential speakers of the target languages of mathematics, and hence competent in their identities as mathematical learners, and others are not.

Far from being isolated from discourses in which deficit and resource perspectives alternate, we find discourses that emphasize language diversity as the means for learner development. The pervasive distinction established between the language of the learner and the language of the teacher and mathematics resonates with the distinction between the language of the learner and the language to be learned in learner studies within classical linguistics (Lo Bianco 2008). The domain mostly assumes the contrast and distance between two major languages framed around a self and other perspective that needs to fulfil a developmental progress from A to B. The language of the learner is understood in terms of the target language to be learned, which is the language that has the upper hand in the hierarchy. The learner must move from A to B and develop her language as she develops her mathematics and herself as a certain type of learner and citizen. Language development becomes an indicator for performing a role in a particular type of mathematical subjectivity, i.e., as the competent problem-solver, skilful in reasoning and argumentation. Despite the potential of a fluid language continuously transforming amongst varied languages or codes, binary discourses remain in the idealization of two major states that naturalize a linear movement from language $\mathrm{A}$ to $\mathrm{B}$, where $\mathrm{A}$ is always the minor language. Such discourses tend to create the language of the teacher and mathematics as mediating the state norm and, as such, shrinking our ways of imagining language or our research otherwise. Healy and Fernandes (2011) discuss how blind learners can develop their mathematics learning as part of the representations of mathematics made available through the language of the teacher and mathematics: "Mathematics learning involves the appropriation of practices associated with the sets of artefacts that have historically come to represent the body of knowledge we call mathematics" (p. 157). In contemporary contexts that aspire to globalized learning but, at the same time, conceal how language politics forms part of identity struggles, this is a profound discussion of the politics of learner representation.

Constructions of the learner come together with discourses on language as the weight of the past that often highlights the starting point from which to transform the learner's linguistic capital. It is part of the norm to construct the learners' backgrounds as more real than their foregrounds (Skovsmose 2005). Foregrounds could be stressed as potential realities crafting learner desires, fabricating identities despite constraints perpetuating inequity. However, learner backgrounds continue to ground our ways of seeing learners and their home contexts in direct contrast to the school institutions, where particular learner identities prevail and shape everyday realities in the mathematics classroom. Warren et al. (2004) suggest the problem of indigenous students in Australia to be not speaking and understanding well both English and the mathematical register: "The language background of Indigenous students can have a major impact on all educational outcomes. Added to this are the subtleties of the mathematics language, its particular linguistic twists and semantic meanings" (p. 37). In mathematics education research, we tend to pay great attention to what or who the learners are, but much less to what they wish to become, and what frames their desires or will to learn. Interestingly, language backgrounds as funds of knowledge are related to emancipatory views of research in the diverse mathematics classroom, while language capital tends to appear in research signalling the culture that brings cultural capital in a context and, paradoxically, asserting certain learner identities as culturally and linguistically poorer. A normative reading of mathematical language capital is that of a learner accumulating specific forms of knowledge, performed in specific linguistic codes, as valued by privileged groups in the school and related institutions like the family and the state.

Representation politics encourages us to reconsider the learner as the imagined global citizen of the curriculum in the sense that, despite the local education policies for language diversity in the mathematics classroom, national or international assessment practices tend to reconfigure a 
certain kind of language user as learner. This learner, despite being allowed to use the home language, is eventually evaluated on how the state language is performed. In this process, the fixity of mathematical language use occurs around an idea of mathematics education as primarily serving the state narrative in a context of global and local cultural struggles. Moreover, the coupling of mathematics and language under the caveat of language diversity does not permit the full realization of learners' cultural or identity diversity.

The representation politics of language and language diversity is entwined with discourses of citizenship where categories of people, such as immigrants, youth or the disabled, fluent in their minor vernaculars, need to develop in certain ways. Such tacit discourses translate through the mathematics curriculum into specific learner identities framed around images of competent problem-solvers or rational reasoning individuals who, despite diversity, need to perform the norms of uniformity. Thus language becomes a paramount concern in the mathematics class. Despite wishes to include the languages of learners, prescriptions on how mathematical language needs to perform do not leave much room for diversity. Language remains a closed, fixed system of representation-a system that serves to represent the Western cultural capital of mathematics itself, but also the 'other' as the ethnic or local identity politics of particular groups. In contrast to the fixity of the language of mathematics, the language of the learner is crafted as in need of developing away from histories of minor languages. The message sent is that the learner from a language-diverse background is free to use the home language, but must soon become socialized in a particular curriculum and schooling context mediated by the language of mathematics and the teacher.

\section{Language diversity and representations of the teacher}

A norm related to the fixity of the language of mathematics is the un-negotiated nature of the language of the teacher. Resources such as textbooks, extra-curricular literature, digital tools and exam papers, as well as international assessment procedures, become governing mechanisms of control. The teacher is governed by being the key mediator and facilitator for the learning of mathematics through such resources. At the same time, the teacher's work is constantly under audit control through learner performance assessment. In contrast to deficit discourses of multilingual learners using such resources poorly, research on teachers' practices highlights an additive consideration of all languages as one unitary language. In this way, language diversity in the mathematics classroom might inform the field about the artificiality of language separation and parallel monolingualism, and the potential of flexible forms of multiple language systems (i.e., translanguaging) by multilingual learners and teachers in mathematical activity.

Based on discourses of the unity of language, Halai and Muzaffar (2016) argue for "a more socio-culturally embedded and inclusive use of language in the classroom instead of an abrupt move from one language to the other as the language of instruction" (p. 58). Even this line of research confronts linguistic and developmental discourses that privilege the view of the language of the teacher and mathematics as the language system for learners to reach in the process of learning mathematics. The label of language learner in relation to the learner's background, perceived or real, is also challenged in that all participants, including the teacher, become language learners due to the need to interact with the so-called standard registers of each language and their analogy to related representations of the world. Despite the contributions to the reframing of language as social action and cultural practice rather than a bounded system of communication, this shift in thinking has come about without sufficient shifts in the practice of research. The assumption persists that it is normal and natural to research the mathematical activity of the learners communicated in the language of the teacher. There is an issue with the forms of mathematical activity omitted due to its expression in languages unknown by researchers and placed in the margins by transcripts published in journals (e.g., oral languages, body languages, languages of the other in multiple genres or codes). When we start thinking of language as unitary in teaching and learning, we omit the privilege of some languages in research in the multilingual mathematics classroom.

Representation politics raises questions about how discourses of language diversity encourage us to approach the teacher of mathematics. The teacher seems to be the autonomous agent who orchestrates codeswitching or translanguaging practices and, at the same time, respects learner histories, supports learners to dream about the future, reconciles harsh feelings and enacts resourceful practices. All this pushes forward an image of a teacher who can do everything, even though she cannot handle, manage or speak multiple languages. The teacher's own language identity is assumed as conforming to state requirements despite the fact that many teachers today are of migrant backgrounds. The ideal teacher is one who makes language diversity work in a local mathematics classroom for the purpose of global mathematics teaching and learning that tend to be captured in universal or cosmopolitan terms that are often inscribed in curricular discourses of "maths for all' reformations. Representation politics helps us to problematize such global demands, interrogate the local, bring forward tensions and dilemmas, and realize that these tensions and dilemmas are not a matter of a teacher alone, but 
of a whole circuit of culture that might compete with other circuits of cultures. School and classroom realities remain at the level not only of teachers' pedagogic and didactic abilities but also at the level of policy images of teaching in contexts of language diversity and institutional teacher education programmes that may or may not encourage translanguaging and other uses of language. Essien et al. (2016) problematize the lack of research attention to the multiple knowledge layers involved in what it means to become a mathematics teacher in multilingual classrooms, one of them being: "awareness of the practices that are privileged" (p. 107).

\section{Some concluding remarks}

In this paper, we focused on the role of language-and particularly language as discourse-in the construction of language diversity in mathematics education research. We drew on indicative research to discuss the study of language diversity, constrained by the recognition of one particular language - as the representation of mathematics, of the teacher and of the learners-being more appropriate than others. We also documented the most recent studies of language diversity that seek to resist the power of certain cultures represented as the essence of civilization in the realm of mathematics as cultural heritage. Implicit in our view of the role of language in the field is that the meaning of language diversity is not tied to the realities researched, but rather produced by and circulated through discourse in tacit and powerful ways. The meaning of language diversity as either learner deficit or pedagogic resource has been developed under the influence of the thinking of dominant cultural groups and communities about what (language of) mathematics and what (language of) teaching and learning are to be taken as preferred and prevailing representations in school practice. Far from an interest in expressing any preference for a meaning of language diversity (we did that in prior research, some of which was in collaboration), we highlight the fact that some widespread shared meanings (e.g., learner deficit, pedagogic resource) are the result of the struggle over meaning among groups and communities. In this respect, language and discourse exercise the role of representing the resulting meaning as natural and culturally neutral, and hence of covering the politics inherent in the meanings represented, that is, the politics of representation.

As already explained, some newer publications in the field have started to challenge prevailing shared views of language diversity in mathematics education, by uncovering the role of language and discourse in the construction and acceptance of meaning. These studies have variably focused on the struggle in the representation of the language of mathematics, of the teacher and of the learners, and its implications for the representation of language diversity. Along these lines of thinking, 'language diversity as pedagogic resource' has been construed as a challenge to 'language diversity as learner deficit' but both meanings are equally constrained by the 'circuit of culture' that represents some cultures and practices as a threat to school mathematics. When one representation of mathematics and language diversity prevails, a hierarchy is produced in the language used to represent the competing representations. Despite the fact that the move towards seeing language as representation politics in the field has already started, more needs to be done in future research so that researchers can gain further awareness of the power of representation as well as the discursive struggle for this power around competing representations of, for example, school mathematics. We need research with a focus on the role of language and discourse in the politics of representation, that is, research approaching the use of language from the perspective of its power to create the fiction of natural meanings and pure realities, and additionally its power to uncover the 'circuit of culture'. This type of research is necessary for the field to produce alternative representations of language diversity in mathematics teaching and learning that are socially and culturally responsible, and that ultimately consider the exclusiveness attributed to specific mathematical cultures as relevant to an understanding of multilingual mathematics education.

Taking into account that we live in a world where semiotic, literary and discursive representations in language use prevail, of which mathematics education is a strong example, we agree with Hall (1997) and Spivak (1988) that the representation politics of language must be taken into consideration. In the example of language use in mathematics education, we need research that is explicitly socio-cultural-political (Planas and Valero 2016) in purpose. This research must make particular discourses explicit, so that they can be challenged and changed. Especially today, at a time when mathematics education research is seriously considering language diversity, we maintain through this paper that a move towards the politics of representation is timely and necessary in order to understand the potential role of language and language diversity in the production of inequity and social change. Such a move can sensitize us to the fact that discourses on language diversity can become trapped in systems of representation that cannot escape othering and, as such, their politics needs to be interrogated. Whilst the notion of language as representation has prevailed in the ways we discuss language and language diversity in mathematics education, far less attention is paid to language politics and to the role of language within cultural and identity struggles. Language and language diversity as part of school-based mathematical practices, and as part of an accepted focus in mathematics education research, tend 
to emphasize semiotic and discursive issues without overtly addressing connections to the public realm. The politics of representation and its potential for mathematics education might allow us to change this.

Acknowledgements Catalan Institute of Advanced Studies and Research-ICREA; EDU2015-65378-P, MINECO/FEDER.

Open Access This article is distributed under the terms of the Creative Commons Attribution 4.0 International License (http://creativeco mmons.org/licenses/by/4.0/), which permits unrestricted use, distribution, and reproduction in any medium, provided you give appropriate credit to the original author(s) and the source, provide a link to the Creative Commons license, and indicate if changes were made.

\section{References}

Austin, J.L., \& Howson, A.G. (1979). Language and mathematical education. Educational Studies in Mathematics, 10(2), 161-197.

Barwell, R. (2016). Formal and informal mathematical discourses: Bakhtin and Vygotsky, dialogue and dialectic. Educational Studies in Mathematics, 92(3), 331-345.

Christianidis, J. (Ed.). (2004). Classics in the history of Greek mathematics. Dordrecht: Kluwer Academic Publishers.

Chronaki, A. (2009). An entry to dialogicality in the maths classroom: Encouraging hybrid learning identities. In M. César \& K. Kumpulainen (Eds.), Social interactions in multicultural settings (pp. 117-144). Rotterdam: Sense Publishers.

Chronaki, A. (2011). "Troubling" essentialist identities: Performative mathematics and the politics of possibility. In M. Kontopodis, C. Wulf \& B. Fichtner (Eds.), Children, development and education: Cultural, historical, anthropological perspectives (pp. 207-226). New York: Springer.

De Freitas, E., \& McAuley, A. (2008). Teaching for diversity by troubling whiteness: Strategies for classrooms in isolated white communities. Race, Ethnicity and Education, 11(4), 429-442.

Deleuze, G., \& Guattari, F. (1987). A thousand plateaus: Capitalism and schizophrenia. Minneapolis: University of Minneapolis Press.

Du Gay, P., Hall, S., Janes, L., Madsen, K. A., Mackay, H., \& Negus, K. (1997). Doing cultural studies. The story of the Sony Walkman. London: Sage.

Duval, R. (1995). Sémiosis et pensée humaine. Registres sémiotiques et apprentissages intellectuels. Bern: Peter Lang.

Edmonds-Wathen (2014). Influences of indigenous language on spatial frames of reference in aboriginal English. Mathematics Education Research Journal, 26(2), 169-192.

Essien, A., Chitera, N., \& Planas, N. (2016). Language diversity in mathematics teacher education. Challenges across three countries. In R. Barwell et al. (Eds.), Mathematics education and language diversity. The 21st ICMI Study (pp. 103-119). New York: Springer.

Foucault, M. (1972). The archaeology of knowledge (1st ed. 1969, Trans. A. M. Sheridan). London: Tavistock.

Gal, S. (1989). Language and political economy. Annual Review of Anthropology, 18, 345-367.

Gorgorió, N., \& Planas, N. (2001). Teaching mathematics in multilingual classrooms. Educational Studies in Mathematics, 47(1), 7-33.

Halai, A., \& Muzaffar, I. (2016). Language of instruction and learners' participation in mathematics. Dynamics of distributive justice in the classroom. In A. Halai \& P. Clarkson (Eds.), Teaching and learning mathematics in multilingual classrooms (pp. 57-72). Rotterdam: Sense Publishers.

Hall, S. (1997). Representation: Cultural representations and signifying practices. London: Sage.

Healy, L., \& Fernandes, S. H. A. A. (2011). The role of gestures in the mathematical practices of those who do not see with their eyes. Educational Studies in Mathematics, 77(2-3), 157-174.

Hunter, R., Civil, M., Herbel-Eisenmann, B., Planas, N., \& Wagner, D. (Eds.). (2018). Mathematical discourse that breaks barriers and creates space for marginalised learners. Rotterdam: Sense Publishers.

Janvier, C. (Ed.). (1987). Problems of representation in the teaching and learning of mathematics. Hillsdale: Lawrence Erlbaum Associates.

Lave, J., \& Wenger, E. (1991). Situated learning: Legitimate peripheral participation. Cambridge: Cambridge University Press.

Lo Bianco, J. (2008). Educational linguistics and education systems. In B. Spolsky \& F. M. Hult (Eds.), Handbook of educational linguistics (pp. 113-126). London: Blackwell.

Mason, J. (1987). What do symbols represent? In C. Janvier (Ed.), Problems of representation in the teaching and learning of mathematics. Hillsdale: Lawrence Erlbaum Associates.

Morgan, C. (2006). What does social semiotics have to offer to mathematics education research? Educational Studies in Mathematics, 61(1-2), 219-245.

Mufwene, S. S. (2002). Colonisation, globalisation, and the future of languages in the twenty-first century. International Journal on Multicultural Societies, 4(2), 162-193.

Pirie, S. (1997). The use of talk in mathematics. In B. Davies \& D. Corson (Eds.), Oral discourse and education (pp. 229-238). New York: Springer.

Planas, N., \& Civil, M. (2013). Language-as-resource and languageas-political: Tensions in the bilingual mathematics classroom. Mathematics Education Research Journal, 25(3), 361-378.

Planas, N., \& Setati-Phakeng, M. (2014). On the process of gaining language as a resource in mathematics education. $Z D M, 46(6)$, 883-893

Planas, N., Morgan, C., \& Schütte, M. (2018). Mathematics education and language. Lessons from two decades of research. In T. Dreyfus, M. Artigue, D. Potari, S. Prediger \& K. Ruthven (Eds.), Developing research in mathematics education. Twenty years of communication, cooperation and collaboration in Europe (pp. 196-210). London: Routledge.

Planas, N., \& Valero, P. (2016). Tracing the socio-cultural-political axis in understanding mathematics education. In Á. Gutiérrez, G. H. Leder \& P. Boero (Eds.), The second handbook of the psychology of mathematics education. The journey continues (pp. 447-479). Rotterdam: Sense Publishers.

Prediger, S., Clarkson, P., \& Bose, A. (2016). Purposefully relating multilingual registers: Building theory and teaching strategies for bilingual learners based on an integration of three traditions. In R. Barwell et al. (Eds.), Mathematics education and language diversity. The 21st ICMI Study (pp. 193-215). New York: Springer.

Radford, L. (2006). The anthropology of meaning. Educational Studies in Mathematics, 61(1-2), 39-65.

Rorty, R. (2009). Philosophy and the mirror of nature (1st edn. 1979). Princeton: Princeton University Press.

Said, E. W. (1997). Covering Islam: How the media and the experts determine how we see the rest of the world. London: Vintage.

Secada, W. G. (1992). Race, ethnicity, social class, language, and achievement in mathematics. In D. A. Grouws (Ed.), Handbook of research on mathematics teaching and learning: A project of the National Council of Teachers of Mathematics (pp. 623-660). New York: Macmillan.

Setati, M., \& Adler, J. (2000). Between languages and discourses: Language practices in primary multilingual mathematics classrooms 
in South Africa. Educational Studies in Mathematics, 43(3), 243-269.

Sfard, A. (2008). Thinking as communicating: Human development, the growth of discourses, and mathematizing. Cambridge: Cambridge University Press.

Skovsmose, O. (2005). Foregrounds and politics of learning obstacles. For the Learning of Mathematics, 25(1), 4-10.

Spivak, G. C. (1988). Can the subaltern speak? Revised edition. In R. C. Morris (Ed.), Can the subaltern speak? Reflection on the history of an idea (pp. 21-79). New York: Columbia University Press.
Steinbring, H. (2005). The construction of new mathematical knowledge in classroom interaction: An epistemological perspective. New York: Springer.

Vergnaud, G. (1997). The nature of mathematical concepts. In T. Nunes \& P. Bryant (Eds.), Learning and teaching mathematics: An international perspective (pp. 5-28). Hove: Taylor \& Francis.

Warren, E., Cooper, T. J., \& Baturo, A. R. (2004). Indigenous students and mathematics: Teachers' perceptions of the role of teacher aides. The Australian Journal of Indigenous Education, 33, 37-46. 